\title{
Nonspecific osteomyelitis of the spine (NOS) in a patient with primary gout due to Lesch-Nyhan syndrome (LNS): case description and literature review
}

\author{
A.A. Vishnevskii, K.V. Kuchinskii
}

St. Petersburg Research Institute of Phthisiopulmonology, Saint Petersburg, Russian Federation

\begin{abstract}
Introduction Lesions of the spine due to gout are rare types of seronegative spondyloarthritis. The article provides a review of the literature of primary and secondary types of gouty spondyloaritritis and presents a clinical example of nonspecific osteomyelitis of the spine (NOS) in a patient with the primary Lesh-Nyhan syndrome (LNS). The aim of the work is to show the complexity of diagnosis and treatment of pyogenic spondylitis in a patient with a genetically predetermined primary gout LNS. Materials and methods Clinical and radiographic assessment of the patient was performed in accordance with the clinical recommendations for the treatment of infectious spondylitis (2018). The effect of surgical treatment was studied with standard scales and questionnaires: ODI, SF-36, VAS, ASIA. Results Due to pain, severe neurological manifestations and instability of the spine, the patient underwent a decompression stabilizing surgery. The final diagnosis of gout tophus lesions of the spine was established with light polarization microscopy. Conclusion Diagnosis and treatment of gout spondyloarthritis is difficult. The clinical case of NOS in a patient with LNS showed that a diagnostic error and incorrect interpretation of the diagnosis may occur if the postoperative material is not verified histologically and bacteriologically. Since radiographic changes in the spine are usually nonspecific in gout, trepanation biopsy and examination of the histological material with polarizing light are necessary to verify the diagnosis.
\end{abstract}

Keywords: gout, Lesh-Nyhan syndrome, spondylitis, spondyloarthritis, surgical treatment

\section{INTRODUCTION}

Nonspecific osteomyelitis of the spine (NOS) is a rare disease that mostly occurs due to various conditions associated with immunodeficiency, disorders of the endocrine and cardiovascular systems [1-2]. Among the systemic autoimmune diseases, gout is encountered in the group of socalled "seronegative spondyloarthritis". There are several scientific literature works devoted to gout spondyloarthritis [3-8]. However, NOS cases due to gout have not been described.

Gout is characterized by an increased content of uric acid in blood (hyperuricemia), deposition of uric acid in the shape of urate crystals (tophus) in the articular and/or periarticular tissues resulting further in the development of aseptic inflammation. Radiographic signs of spinal lesions in gout develop for a long time and are nonspecific. They should be differentiated from pyogenic and granulomatous spondylitis, primary and secondary tumor lesions of the spine [9]. If spondylitis is not verified histologically and bacteriologically, diagnostic errors may happen, the rate of which reaches 60-90 \% [1, 2, 10-13].

Primary and secondary types of gout are distinguished. The primary types of gout include genetically predetermined diseases, one of which is Lesch-Nyhan syndrome (LNS) (ICD-10, E79.1) [1417]. LNS is an extremely rare hereditary recessive $\mathrm{X}$-linked disease that occurs only in males and is characterized by various mutations of the gene located in Xq26-q27. The disease causes a disorder of purine metabolism due to the development of a deficiency of the enzyme hypoxanthine-guanine phosphoribosyltransferase (HGPRT) [18-20]. The incidence of the disease varies in different populations, $1: 250000$ or 380000 persons [19].

Currently, more than 300 mutations have been described that define a wide range of clinical signs of gouty manifestations from isolated hyperuricemia and related to it pathology (gouty tophus, nephrolithiasis, etc.) to severe pathology of the central nervous system $[18,20,21]$. Despite the rarity of these mutations, a large number of studies (more than 200) have been devoted to investigation of LNS [18, 22]. In some cases, the presence of hyperuricemia is not combined with any neurological or behavioral disorders and is associated with a partial deficiency of HGPRT. This type of the disease is called HGPRT-associated gout or Kelly-Segmiller syndrome [17].

(1) Vishnevskii A.A. Kuchinskii K.V., Nonspecific osteomyelitis of the spine (NOS) in a patient with primary gout due to Lesch-Nyhan syndrome (LNS): case description and literature review. Genij Ortopedii, 2020, vol. 26, no 1, pp. 103-107. DOI 10.18019/10284427-2020-26-1-103-107 
Clinically, LNS is manifested by a triad of symptoms: laboratory changes (hyperuricemia and hyperuricosuria), pathology of the nervous system, and behavioral disorders [15-17]. A delay in psychomotor development in a child with LNS starts from the first year of life, and subsequently motor disorders develop, such as spasticity and choreoathetosis, while pain sensitivity remains intact [23-26]. A typical sign of the disease is auto-aggressive actions; patients bite and scratch their lips, fingers, and nails. Due to these actions, they become nervous, show aggression towards other people, and also scream from the pain they cause to themselves $[14,23,24]$. Such patients, if they have no targeted treatment, are supervised by psychiatrists, since similar self-traumatic behavior occurs in other pathological conditions, such as nonspecific mental retardation, autism, Tourette syndrome, Cornelia de Lange syndrome, Rett syndrome, Riley-Day syndrome, neurocanthocytosis, hereditary neuropathies of the first type etc.

The purpose of the work was to show the complexity of the diagnosis and treatment of pyogenic spondylitis in a patient with genetically predetermined primary gout in Lesch-Nyhan syndrome (LNS).

\section{MATERIAL AND METHODS}

The study reviewed the literature sources available in the English and Russian language information databases PubMed, Clinical Key, Clinical Trials, Cochrane Library, eLIBRARY on the problem of surgical treatment of infectious spondylitis using the keywords spondylitis, gout, Lesch-Nyhan syndrome, spondylitis, surgical treatment.

Examination and treatment of the patient was performed in accordance with the clinical guidelines for surgical treatment of spondylitis (2018). The diagnosis was confirmed by histological study of the postoperative material and light polarizing microscopy. The etiological agent was identified with the molecular genetic method of studying bacteria and cultures of the surgical material (tissue from the lesion, pus, granulation) on a liquid nutrient medium (Middlebrook 7H9, Becton Dickinson) and on dense nutrient media Levenshtein-Jensen and Finn II with fluorescence detection of microorganisms growth (BACTEC MGIT 960, Becton Dickinson and Kompani, USA). Surgical treatment efficiency was studied according to standard evaluation systems: quality of life assessment according to the ODI (Oswestry disability test) and SF-36 questionnaires, the visual analogue scale (VAS), the neurological scale ASIA (1996), and spinal instability according to the SINS scale (2012).

\section{RESULTS}

We describe a NOS case in a patient with LNS which presented a diagnostic difficulty. Patient P., 40 years old, was admitted to the clinic of St. Petersburg Institute of Phthisiopulmonology diagnosed with nonspecific osteomyelitis of the spine at L4-L5 level after stabilizing decompression surgery on the spine

Case history The patient is ill since 2014 when he started to feel pain in the lumbar spine and a body temperature rise. He was treated at the hospital of his residence and diagnosed with nonspecific osteomyelitis of the spine at L4-L5 level. He passed a course of conservative treatment with broad-spectrum antibiotics for a month. Pain in the spine relieved after two months and he ambulated independently. But three years later, he was not able to walk independently due to the weakness in his legs.

In March 2017, the patient was admitted to the neurosurgical department at his residence hospital. MRI of the lumbosacral spine from 14.03.2017 revealed degenerative changes in the spine with severe stenosis of the spinal canal and compression of the nerve roots at the level of L2-L5. After further examination (CT and MRI), a staged surgical treatment was undertaken, microsurgical decompression of the spinal canal at the level of L2-S1 was performed from the posterior approach first and anterolateral fusion at the level of L3-L5 at the second stage. Subsequently, antibiotic therapy was administered (amoxacillin $1.2 \times 3$ times, $\mathrm{i} / \mathrm{v}$ ) for 10 days. After its completion, the patient began to notice a rise in the body temperature to $39^{\circ}$. A sinus appeared in the lumbar region. Staphylococcus aureus $\left(\right.$ MRSA $\left.\times 10^{5}\right)$, sensitive to linezolid and vancomycin, was isolated from the fistula.

The patient passed a course of antibiotic therapy again, and improved. Back pain relieved, body temperature returned to normal, the sinus passage closed. A radiographic checking revealed signs of vertebral body destruction at L4-L5 by one half of their height with the formation of left-side scoliosis and stenosis of the spinal canal at the level of L4-L5 (Fig. 1). 


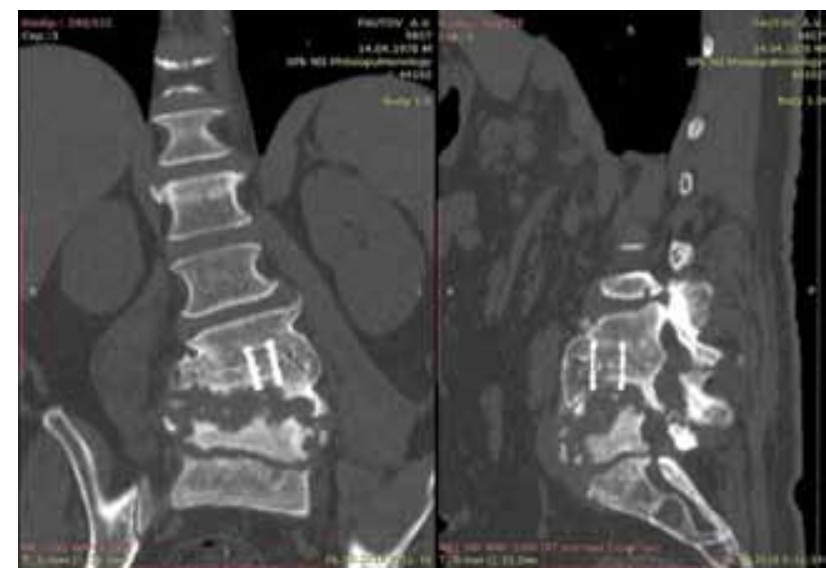

Fig. 1 Frontal and sagittal views in CT scan of the lumbosacral spine. A titanium implant is installed in the middle of bodies L3 and L4 (Piramesh, Medtronic, USA). The lower end of the implant enters into the destruction cavity between the remains of the vertebral bodies of L4 and L5. The outgrowth of bone tissue with the formation of exostosis, narrowing the spinal canal at the level of L4-L5 by more than $50 \%$. Suspicion of a purulent inflammatory process in the right lumbar muscle and the muscle straightening the spine

From the history of the case, it was known that the patient was lagging behind in development from the first year of his life. He began to pronounce the first words when he was close to two years of age. Dysarthria was characterized by the following: his speech was slow, fuzzy, and he had difficulty to pronounce separate sounds. In childhood, he suffered auto-aggression, he bit his lips hard, bit his fingers and toes. At the age of 10 , the patient had osteomyelitis of the lower jaw and terminal phalanges of the fingers. In adolescence, he felt pain and limited mobility in large joints. Gouty arthritis was detected with a high level of uric acid only at the age of 15 . Since that time, he has been taking xanthioxidase inhibitors (allopurinol) and psychotropic drugs.

Upon admission to the clinic of St. Petersburg Institute of Phthisiopulmonology, his condition was relatively satisfactory; he complained of severe pain in the lumbar region when changing position (Table 1), weakness in the legs. He did not walk for more than six months. Deformation of the oral cavity and lack of teeth were revealed by examination (Fig. 2).

Table 1

Main clinical indicators of patient P., 40 years old, before and after surgery (explanation in the text)

\begin{tabular}{|l|c|c|}
\hline & Before surgery & After surgery \\
\hline LP/BP (points) & $5 / 6$ & $1 / 2$ \\
\hline ODI (points) & 82 & 48 \\
\hline SINS (points) & 6 & 0 \\
\hline $\begin{array}{l}\text { Type of neurological } \\
\text { deficit according } \\
\text { to AOs/Frankel }\end{array}$ & $\mathrm{C}$ & $\mathrm{C}$ \\
\hline ASIA (points) & $68 / 102$ & $88 / 104$ \\
\hline
\end{tabular}

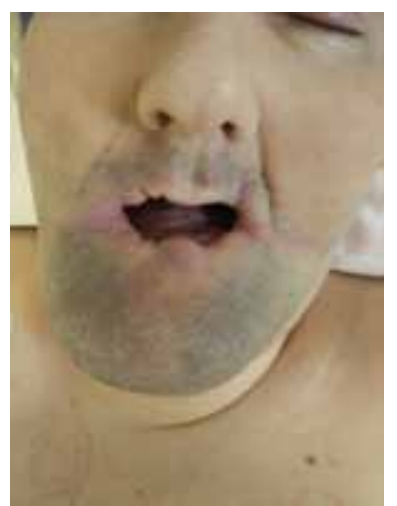

Fig. 2 Photo of patient P., 40 years old, with LeschNyhan syndrome
Locally, tension of the spine muscles, pain on palpation in the projection of the spinous processes of L3-L5. The load along the axis of the spine was painful. In the knee joints, an increase in muscle tonus of a spastic type and a decrease in the strength of the thighs down to 2-3 points were revealed. The strength in the extensors of the left foot was 0 points, and on the right side reduced to 2 points, symptoms of tension from $30^{\circ}$ on the right, $20^{\circ}$ on the left. There was no Achilles reflex on both sides.

American Spine Injury Association (ASIA) score was 68/102, Oswestry Disability Index (ODI) 82 points, SF-36 (GH-40, Pf-15, RP-0, RE-0, BP-41, VT-40, MH-36); there were marked disorders in the patient's physical state and signs of deep depression.

Blood test counts revealed moderate anemia (hemoglobin $112 \mathrm{~g} /$, leukocytosis $\left(12.0 \times 10^{6}\right)$, increased ESR up to $62 \mathrm{~mm} /$ hour. Biochemical analysis of blood detected a systemic inflammatory response syndrome (fibrinogen 6.0 (normal 2-4 g/l), C-reactive protein (CRP) - $32.0 \mathrm{mg} / \mathrm{l}$ (normal 0-6 mg/l), increased serum uric acid up to $560.0 \mu \mathrm{mol} / \mathrm{l}$ (normal 210-420 $\mu \mathrm{mol} / \mathrm{l}$ ).

Based on anamnestic and clinical laboratory data, a diagnosis was osteomyelitis of the L4-L5 vertebrae, chronic progressive course, condition after spinal surgery, bone fusion L3-L4 and spinal stenosis. Complication: bilateral pyramidal insufficiency, lower paraparesis (type $\mathrm{C}$ according to AOs/Frankel). Concomitant diseases: primary chronic gout, chronic spondylitis, tophus type (Lesch-Nyhan syndrome); encephalopathy with moderate cognitive impairment and dysarthria.

After additional examination with image techniques (functional spondylograms, CT and MRI), a stabilizing decompression operation on the spine was performed. Sequestrectomy, necrectomy, resection of L3-L4 vertebral bodies, spinal canal decompression, meningoradiculolysis were performed from left-side through the extraperitoneal approach. Fixation of the 
anterior column of the spine was spinal fusion with a combined titanium implant (Pyramesh, autobone and Reprobona granules; Metronik, USA). In the postoperative period, parenteral antibiotic therapy was administered for four weeks. After the operation, the patient noted an increase in the strength of the thigh up to 4 points, in the right foot up to 4 points; however, deep paresis of the extensors of the foot persisted on the left. The patient was put on crutches seven days after surgery. According to questionnaires and tests after one month, a positive dynamics was observed (ASIA 88/104 points, ODI - 48 points, VAS - 1-2 points).

Histological study of the postoperative material revealed a diffuse inflammatory cell infiltration with areas of tissue necrosis. Around that site, there was an inflammatory reaction with a cell response from histiocytes, lymphoid, plasma cells and a large number of giant cells containing phagocytized crystals. Since the revealed changes are characteristic of bone inflammation, the final diagnosis of gout was established using polarizing light microscopy.

\section{DISCUSSION}

The case report showed that the patient with confirmed LNS in childhood had a high risk of infectious complications. This was evidenced by the infectious lesions of the skeleton bones sustained at the age of 10 years and spondylodiscitis at the level of L4-L5 at the age of 36 years.

The difficulty in the differential diagnosis of aseptic inflammation in gout and purulent inflammation in the spine is due to the fact that destructive signs in osteoarticular system in gouty spondylitis occur prior to verification of the diagnosis. The systemic inflammatory response detected in these diseases is nonspecific and can be as a marker of treatment efficiency [1]. Clinical manifestations of gouty spondylitis are also not pathognomonic. Only with a large volume of tophus masses spreading from the intervertebral joints, a pronounced vertebrogenic syndrome, radiculo-ischemic syndromes may occur due to spinal canal stenosis [27].

Based on current views, three components should be analyzed to establish the diagnosis of spondylitis [1, 2, 10]. Along with the detection of a local focus of inflammation in the spine, it is necessary to isolate the pathogen from the blood or focus and describe the type of systemic inflammatory response [1]. The main means in the early diagnosis of spondylitis are MRI and osteoscintigraphy, which detect diseases already after three days since the onset of initial symptoms (the sensitivity of these methods reaches $86-95 \%$ ) [1].

In the early period of the disease, CT and MRI of the spine may be useful for the diagnosis of gouty spondylitis. With MRI in the T2 WI mode, a hyperintense signal with clear uneven contours is detected and in the T1 WI mode with a hypo-intense rim of osteosclerosis on the periphery (tophus). In the area of intervertebral joints, there is effusion and asymmetric edema in periarticular soft tissues [3,6]. Compared to ultrasound and MRI, spiral CT enables to more accurately differentiate tophus masses. According to our data, the sensitivity of the method is $86 \%$ and it is capable to identify tophus localized both in the joints, tendons, and in paravertebral tissues.

\section{CONCLUSION}

Diagnosis and treatment of gouty spondylitis is difficult. The clinical case of NOS in a patient with LNS showed that a diagnostic error and misinterpretation of the diagnosis may occur if histological and bacteriological verification of the postoperative material is absent. Since radiographic changes in the spine are usually nonspecific in gout, trepanation biopsy and examination of the histological

material with polarizing light are necessary to verify the diagnosis $[11,12]$. Subsequently, in accordance with the clinical recommendations for the treatment of gout, along with targeted antibiotic therapy for at least 4-6 weeks, the patient should receive xanthine oxidase inhibitors (to reduce the production of uric acid), as well as drugs to accelerate its excretion in normal renal function (probenecid) [28-30].

\section{REFERENCES}

1. Shchedrenok V.V., Moguchaia O.V., Sebelev K.I., eds. Zabolevaniia pozvonochnika i spinnogo mozga. Gl. 9: Gnoino-vospalitelnye zabolevaniia pozvonochnika i spinnogo mozga [Diseases of the Spine and Spinal Cord. Ch. 9: Purulent inflammatory diseases of the spine and spinal cord]. Moscow, Medpress-inform, 2018, gl. 9, pp. 274-310. (in Russian)

2. Vetrile S.T., Morozov A.K., Kuleshov A.A., Kolbovskii D.A. Diagnostika i khirurgicheskoe lechenie nespetsificheskogo gematogennogo osteomielita pozvonochnika [Diagnosis and surgical treatment of non-specific hematogenous osteomyelitis of the spine]. M., TsITO, 2012, 191 p. (in Russian)

3. Vishnevskii A.A. Tofusnoe porazhenie poiasnichnogo otdela pozvonochnika pri podagre [Tophaceous involvement of the lumbar spine for gout]. Trudnyi Patsient, 2018, vol. 16, no. 7, pp. 40-43. (in Russian) 
4. Zebouni L., Helliwell P.S., Howe A., Wright V. Gait analysis in ankylosing spondylitis. Ann. Rheum. Dis., 1992, vol. 51, no. 7, pp. 898-899.

5. Staub-Schmidt T., Chaouat A., Rey D., Bloch J.G., Christmann D. Spinal involvement in gout. Arthritis Rheum., 1995, vol. 38, no. 1, pp. 139-141.

6. Sousa A.W., Fontenele S., Carrete H. Jr., Fernandes A.R., Ferrari A.J. Involvement of the thoracic spine in tophaceous gout. A case report. Clin. Exp. Rheumatol., 2002, vol. 20, no. 2, pp. 228-230.

7. Yen P.S., Lin J.F., Chen S.Y., Lin S.Z. Tophaceous gout of the lumbar spine mimicking infectious spondylodiscitis and epidural abscess: MR imaging findings. J. Clin. Neurosci., 2005, vol. 12, no. 1, pp. 44-46.

8. Niva M., Tallroth K., Konttinen Y.T. Tophus in the odontoid process of C2. Clin. Exp. Rheumatol., 2006, vol. 24, no. 1, pp. 112.

9. Justiniano M., Colmegna I., Cuchacovich R., Espinoza L.R. Spondyloarthritis as a presentation of gouty arthritis. J. Rheumatol., 2007, vol. 34, no. 5, pp. 1157-1158.

10.Carragee E.J. Pyogenic vertebral osteomyelitis. J. Bone Joint Surg. Am., 1997, vol. 79, no. 6, pp. 874-880.

11.De Lucas E.M., González-Mandly A., Gutiérrez A., Pellón R., Martín-Cuesta L., Izquierdo J., Sánchez E., Ruiz E., Quintana F. CTguided fine-needle aspiration in vertebral osteomyelitis: true usefulness of a common practice. Clin. Rheumatol., 2009, vol. 28, no. 3, pp. 315-320. DOI: 10.1007/s10067-008-1051-5.

12.McNamara A.L., Dickerson E.C., Gomez-Hassan D.M., Cinti S.K., Srinivasan A. Yield of image-guided needle biopsy for infectious discitis: A systematic review and meta-analysis. AJNR Am. J. Neuroradiol., 2017, vol. 38, no. 10, pp. $2021-2027$. DOI: 10.3174 /ajnr.A5337.

13.Schlesinger N. Diagnosis of gout: clinical, laboratory, and radiologic findings. Am. J. Manag. Care, 2005, vol. 11, no. 15 Suppl., pp. S443-S450; quiz. S465-S468.

14.Iablonskaia M.I., Novikov P.V., Agapov E.G., Zolkina I.V., Iureva E.A., Kharabadze M.N. Osobennosti kliniko-laboratornoi diagnostiki sindroma Lesha-Naikhana i sovremennye vozmozhnosti terapii [Special characteristics of clinical-and-laboratory diagnostics of Lesch-Nyhan syndrome and modern therapy scopes]. Rossiiskii Vestnik Perinatologii i Pediatrii, 2015, vol. 60, no. 4, pp. 57-62. (in Russian)

15.Lesch M., Nyhan W.L. A familial disorder of uric acid metabolism and central nervous system function. Am. J. Med., 1964, vol. 36, pp. 561-570. DOI: 10.1016/0002-9343(64)90104-4.

16.Nyhan W.L. The recognition of Lesch-Nyhan syndrome as an inborn error of purine metabolism. J. Inherit. Metab. Dis., 1997, vol. 20, no. 2, pp. 171-178.

17.Seegmiller J.E., Rosenbloom F.M., Kelley W.N. Enzyme defect associated with a sex-linked human neurological disorder and excessive purine synthesis. Science, 1967, vol. 155, no. 3770, pp. 1682-1684.

18.Duan J., Nilsson L., Lambert B. Structural and functional analysis of mutations at the human hypoxanthine phosphoribosyl transferase (HPRT1) locus. Hum. Mutat., 2004, vol. 23, no. 6, pp. 599-611.

19.Torres R.J., Puig J.G. Hypoxanthine deregulates genes involved in early neuronal development. Implications in Lesch-Nyhan disease pathogenesis. J. Inherit. Metab. Dis., 2015, vol. 38, no. 6, pp. 1109-1118. DOI: 10.1007/s10545-015-9854-4.

20. Yamada Y., Nomura N., Yamada K., Wakamatsu N. Molecular analysis of HPRT deficiencies: an update of the spectrum of Asian mutations with novel mutations. Mol. Genet. Metab., 2007, vol. 90, no. 1, pp. 70-76.

21.Jinnah H.A., De Gregorio L., Harris J.C., Nyhan W.L., O'Neill J.P. The spectrum of inherited mutations causing HPRT deficiency: 75 new cases and a review of 196 previously reported cases. Mutat. Res., 2000, vol. 463, no. 3, pp. 309-326.

22.Jinnah H.A., Ceballos-Picot I., Torres R.J., Visser J.E., Schretlen D.J., Verdu A., Laróvere L.E., Chen C.J., Cossu A., Wu C.H., Sampat R., Chang S.J., De Kremer R.D., Nyhan W., Harris J.C., Reich S.G., Puig J.G.; Lesch-Nyhan Disease International Study Group. Attenuated variants of Lesch-Nyhan disease. Brain, 2010, vol. 133, Pt. 3, pp. 671-689. DOI: 10.1093/brain/awq013.

23.Fu R., Jinnah H.A. Genotype-phenotype correlations in Lesch-Nyhan disease: moving beyond the gene. J. Biol. Chem., 2012, vol. 287, no. 5, pp. 2997-3008. DOI: 10.1074/jbc.M111.317701.

24.Eliseev M.S., Barskova V.G. Bolezn Lesha-Nikhena: klinicheskie proiavleniia i variant techeniia, analiz sobstvennogo opyta [Lesch-Nyhan disease: clinical manifestations and course variants, analysis of own experience]. Sovremennaia Revmatologiia, 2010, no. 3, pp. 47-52. (in Russian)

25.Torres R.J., Puig J.G., Ceballos-Picot I. Clinical utility gene card for: Lesch-Nyhan syndrome. Eur. J. Hum. Genet., 2011, vol. 19, no. 1, pp. preceeding 118-120. DOI: 10.1038/ejhg.2010.109.

26.Barrett K., Miller M.L., Wilson J.T. Tophaceous gout of the spine mimicking epidural infection: case report and review of the literature. Neurosurgery, 2001, vol. 48, no. 5, pp. 1170-1172.

27.Maksymowych W.P., Chiowchanwisawakit P., Clare T., Pedersen S., Østergaard M., Lambert R.G. Inflammatory lesions of the spine on magnetic resonance imaging predict the development of new syndesmophytes in ankylosing spondylitis: evidence of a relationship between inflammation and new bone formation. Arthritis Rheum., 2009, vol. 60, no. 1, pp. 93-102. DOI: 10.1002/art.24132.

28.Mejía-Chew C., Torres R.J., De Miguel E., Puig J.G. Resolution of massive tophaceous gout with three urate-lowering drugs. Am. J. Med., 2013, vol. 126, no. 11, pp. e9-e10. DOI: 10.1016/j.amjmed.2013.05.009.

29.Torres R.J., Prior C., Puig J.G. Efficacy and safety of allopurinol in patients with hypoxanthine-guanine phosphoribosyl transferase deficiency. Metabolism, 2007, vol. 56, no. 9, pp. 1179-1186.

30.Tsurko V.V., Gromova M.A. Obshchie printsipy i osnovnye rekomendatsii po vedeniiu i lecheniiu patsientov s podagroi po materialam obnovlennykh evropeiskikh rekomendatsii [General principles and main recommendations on the management and treatment of patients with gout according to the materials of updates European recommendations]. Consilium Medicum, 2017, no. 12, pp. 20-24. (in Russian)

Received: 22.08.2019

\section{Information about the authors:}

1. Arkadii A. Vishnevskii, M.D., Ph.D.,

St. Petersburg Research Institute of Phthisiopulmonology, Saint Petersburg, Russian Federation,

E-mail: vichnevsky@mail.ru

2. Kirill V. Kuchinskii,

St. Petersburg Research Institute of Phthisiopulmonology, Saint Petersburg, Russian Federation 